\title{
Conditioned taste aversion in Philippine rice rats ( $R$. r. mindanensis): Comparisons among drugs, dosages, modes of administration, and sexes
}

\author{
STEPHEN A. SHUMAKE, RAY T. STERNER, STANLEY E. GADDIS, \\ and KENNETH A. CRANE \\ Denver Wildlife Research Center, Denver, Colorado
}

\begin{abstract}
The effects of select drugs, dosages, and modes of administration upon learned taste aversions were compared among groups of wild-caught male and female Philippine rice rats $(R . r$. mindanensis). Experiment 1 compared two-choice saccharin aversions for 28 days among groups intubated with copper sulfate, cyclophosphamide, lithium chloride, red squill, sodium chloride (control), or deionized water (control). Main results were that $375 \mathrm{mg} / \mathrm{kg}$ lithium chloride produced the greatest sustained aversions, whereas $198 \mathrm{mg} / \mathrm{kg}$ cyclophosphamide and $210 \mathrm{mg} / \mathrm{kg}$ red squill produced moderate aversions, with males showing more resistance to extinction than females. Experiment 2 compared saccharin aversion among matched groups of male and female rats that received low $(36 \mathrm{mg} / \mathrm{kg})$, moderate $(105 \mathrm{mg} / \mathrm{kg})$, or high $(368 \mathrm{mg} / \mathrm{kg})$ dosages of lithium by gavage, ip injection, or ingestion. Sex differences in rates of extinction were found for the ingestion and injection-dosed rats, but no sex difference was again found for rats dosed by gavage. A significant mode $X$ day interaction indicated that extinction progressed more rapidly for rats dosed by gavage. For all modes of administration, high dosages yielded intense 28-day aversion, moderate dosages produced intermediate 3-5 day aversion, and low dosages caused no aversion.
\end{abstract}

If a rat is subjected to ionizing radiation, dosed with certain drugs, or given other forms of physical stress shortly after tasting a novel-flavored substance, subsequent intake and preference for that substance is reduced. This effect has been termed conditioned taste aversion (CTA). Since its first demonstration (Garcia, Kimeldorf, \& Koelling, 1955), CTA has been extensively studied with a variety of flavors, drugs, and species (cf. Riley \& Clarke, 1977). Factors that reliably affect CTA include strength of the taste stimulus, severity of druginduced illness, and length of time between consumption and illness (Garcia, Hankins, \& Rusiniak, 1974). Consumption levels of illness-inducing drug or toxin are primarily controlled by taste stimuli detected in association with postingestional effects (Rusiniak, Garcia, \& Hankins, 1976).

The majority of the 632 studies cited by Riley and Clarke (1977) have involved: (1) albino rats, (2) ip

This research was supported in part with funds provided to the U.S. Fish and Wildlife Service by the U.S. Agency for International Development, under the project "Control of Vertebrate Pests," PASA ID/TAB-473-1-67. We thank Diane Horton and Diane Tipton for assistance in data collection, and Paige Groninger for help with data analyses. Charles P. Breidenstein provided helpful consultation regarding research designs. Requests for reprints should be addressed to Stephen Shumake, Denver Wildlife Research Center, Building 16, Federal Center, Denver, Colorado 80225 . injection or stomach-tube intubation (gavage) of $\mathrm{LiCl}$, (3) water-deprivation schedules, (4) sodium saccharin as the novel taste substance, (5) two-bottle taste-preference tests of $<2$ weeks' duration, and (6) 2-3-day postdrug recovery period to allow dissipation of early drug effects. CTA effects of various rodenticides have been compared with $\mathrm{LiCl}$-induced aversion, and the CTA effects of route of drug administration have been examined using albino rats and short-term tests of aversion (Nachman \& Ashe, 1973; Nachman \& Hartley, 1975). The current studies sought to investigate the effects of select drugs, dosages, and modes of drug administration upon long-term saccharin aversions of a species of wild rodent (i.e., Rattus rattus mindanensis).

\section{EXPERIMENT 1}

Nachman and Hartley (1975) examined the CTA effects of several compounds (i.e., red squill, sodium fluoroacetate, copper sulfate, thallium sulfate, warfarin, sodium cyanide, strychnine sulfate, and lithium chloride). The Nachman and Hartley (1975) procedures involved albino rats, a single-choice test procedure, and ip injection of dosages. Experiment 1 was designed to partially replicate and extend these findings. This involved assessments of relative CTA effectiveness associated with four drugs: copper 
sulfate ( $\left.\mathrm{CuSO}_{4}\right)$, cyclophosphamide (Cyclo), lithium chloride ( $\mathrm{LiCl})$, and red squill (RS). Extension of procedures was based on the use of wild Philippine rice rats ( $R$. $r$. mindanensis) and a sustained 28-day extinction test.

\section{Method}

Subjects and Apparatus. Thirty-six (18 male and 18 female) wild-caught Philippine rice rats were used. The rats were shipped by air to the Denver Wildlife Research Center from the vicinity of Los Baños, The Philippines, and allowed a minimum of 3 weeks' acclimation before research was initiated. The rats ranged in body weight from 190 to $260 \mathrm{~g}$ at the start of the study. Their ages were unknown but judged to be between 9 and 20 months.

Throughout the experiment, the rats were housed in individual wire-mesh cages $(25 \times 20 \times 18 \mathrm{~cm})$ located in a temperaturecontrolled room $\left(25^{\circ} \pm 2^{\circ} \mathrm{C}\right)$. A 12:12-h light-dark schedule was in effect (0600-1759 and 1800-0559 h MST, respectively). All rats were fed a basal diet of Purina Rat Chow ad lib; fluid consumption served as the main dependent variable (see Procedures).

Each cage was modified to allow standardization of fluid presentation. A Plexiglas spacer $(9.0 \times .25 \times 1.0 \mathrm{~cm})$, with two 8.0 $\mathrm{mm}$ spout-sized holes drilled $3.70 \mathrm{~cm}$ apart, was attached to the front of each housing cage. During drink sessions, the stainless steel spouts of two 450-ml bottles were inserted through the holes and attached to the cage fronts with bottle springs. Water bottles were weighed to the nearest $10 \mathrm{~g}$ to measure fluid intakes.

Drugg. Four drugs were evaluated for CTA éffectiveness: CuSO, (J. T. Baker Chemical Co., Phillipsburg, N.J.), Cyclo (ICN Pharmaceuticals, Plainview, N.Y.), LiCl (Lithium Corp. of America, Bessemer City, N. Dak.), and RS (MOK Co., Minneapolis). All solutions, including $\mathrm{NaCl}$, were prepared on a wt/wt basis in deionized $\mathrm{H}_{2} \mathrm{O}$. A previous pilot test had indicated that $\mathrm{mg} / \mathrm{kg}$ dosage levels used in the Nachman and Hartley (1975) study were insufficient for producing either initial or sustained CTA in wild Philippine rats. The dosages administered to rats in the respective groups of Experiment 1 were: $30 \mathrm{mg} / \mathrm{kg}$ CuSO $_{4}$, $198 \mathrm{mg} / \mathrm{kg}$ Cyclo, $375 \mathrm{mg} / \mathrm{kg} \mathrm{LiCl}, 210 \mathrm{mg} / \mathrm{kg}$ RS, $375 \mathrm{mg} / \mathrm{kg}$ $\mathrm{NaCl}$, and volumes of $\mathrm{H}_{2} \mathrm{O}$ matching the LiCl-dosed rats (.5$1.8 \mathrm{cc}$ ).

Procedures. The 36 rats were assigned to six groups, each consisting of 3 males and 3 females. The rats were rank-ordered according to weight and randomly assigned to groups with the restriction that one rat be placed in each group before proceeding with subsequent assignments. This procedure was intended to provide similar weight distributions among the rats in the six groups. Throughout the experiments, all rats were maintained on a 2-h/day fluid-availability schedule (i.e., 22-h fluid deprivation). The procedure consisted of four successive phases.

(1) 14-day deprivation-adjustment phase. All rats were allowed 14 days' adjustment to the 22 -h water-deprivation regimen and were given only 2 -h daily access to two water bottles ( $450 \mathrm{ml}$ cap.).

(2) I-day saccharin-drug phase. On Day 15, two bottles containing a $.25 \% \mathrm{wt} / \mathrm{wt}$ mixture of saccharin-flavored $\mathrm{H}_{2} \mathrm{O}$ (No. S-1002 saccharin, Sigma Chemical Corp., St. Louis, Mo.) were presented to each rat. Immediately following this drink session, each rat was dosed by intragastric intubation (gavage) with a specified amount of a particular drug. The 2-h drink sessions of each group were staggered at 15-min intervals to ensure that the doses were given within 12 min after the saccharin-flavored $\mathrm{H}_{2} \mathrm{O}$ was removed.

The gavage procedure involved restraining each rat supine on its back, spreading its jaws with a hemostat, inserting a 20-ga $38-\mathrm{mm}$ intubation needle through the esophagus into the stomach, depositing the contents of a 2-cc disposable syringe $(.50-1.80 \mathrm{cc})$ within $30-60 \mathrm{sec}$, withdrawing the intubation needle, and returning each rat to its cage.

(3) 2-day drug-recovery phase. Days 16 and 17 consisted of 2 $h$ /day presentations of unflavored tap $\mathrm{H}_{2} \mathrm{O}$ in both bottles. This was to preclude direct effects of the drugs from distorting preference data.
(4) 28-day CTA-assessment phase. On Days 18-46, all rats were presented with a two-bottle preference test of $.25 \%$ saccharinflavored tap $\mathrm{H}_{2} \mathrm{O}$ and unflavored tap $\mathrm{H}_{2} \mathrm{O}$ during cach 2-h session. Bottle positions were alternated each day to control for possible position biases.

Data and statistical analyses. The measure of CTA strength used to quantify the preference data was a saccharin-flavor aversion in$\operatorname{dex}(\mathrm{AI})$. The AI for each rat on each day was calculated by the formula $\mathrm{AI}=1.0$ - [Saccharin-flavored $\mathrm{H}_{2} \mathrm{O}$ intake (g)/Unflavored $\mathrm{H}_{2} \mathrm{O}$ intake + Saccharin-flavored $\mathrm{H}_{2} \mathrm{O}$ intake (g)]. AI values approaching 1.0 indicated complete aversion, whereas values approaching 0.0 indicated total preference for saccharin. A second variable, number of days during the 28-day CTA-assessment phase that AIs exceeded .75, was used to assess relative durations of CTA effect among groups.

The AI scores were analyzed as a 6 (drug) $\times 2$ (sex) $\times 28$ (day) complete factorial, with the day variable treated as a repeated-measures factor (Winer, 1971). A two-way analysis of variance-6 (drug) $\times$ 2 (sex)-was computed for the number of days that AIs $>.75$ for each rat during the CTA-assessment phase. Post hoc mean comparisons were computed for significant treatment effects (Duncan, 1955), and a significance level of .05 was used with all statistical tests.

\section{Results and Discussion}

As shown in Figure 1, $\mathrm{LiCl}$ at $375 \mathrm{mg} / \mathrm{kg}$ produced a sustained aversion effect (AIs $>.80$ ) throughout the 28-Day CTA-assessment phase. Cyclo $(198 \mathrm{mg} / \mathrm{kg})$ and $\mathrm{RS}(210 \mathrm{mg} / \mathrm{kg})$ produced high levels of CTA (AIs $>.80$ ) for up to 6 days, but these effects decreased beyond Day 14 to a level of approximately .60 . The drug main effect $[F(5,24)=$ $15.92, \mathrm{p}<.05]$ indicated that $\mathrm{LiCl}$ produced significantly greater AIs than all other drugs, whereas Cyclo and RS produced intermediate CTA relative to $\mathrm{CuSO}_{4}, \mathrm{H}_{2} \mathrm{O}$, and $\mathrm{NaCl}$. These latter treatments produced no CTA. The day main effect $[F(27,648)=$ $8.55, p<.05]$ represented overall extinction and was primarily attributed to the Cyclo and RS groups.

Analyses of interaction terms indicated significant effects for drug $\times$ sex $\times$ day $[F(135,648)=1.44, p<$ $.05]$, drug $\times$ day $[F(135,648)=1.60, p<.05]$, and sex
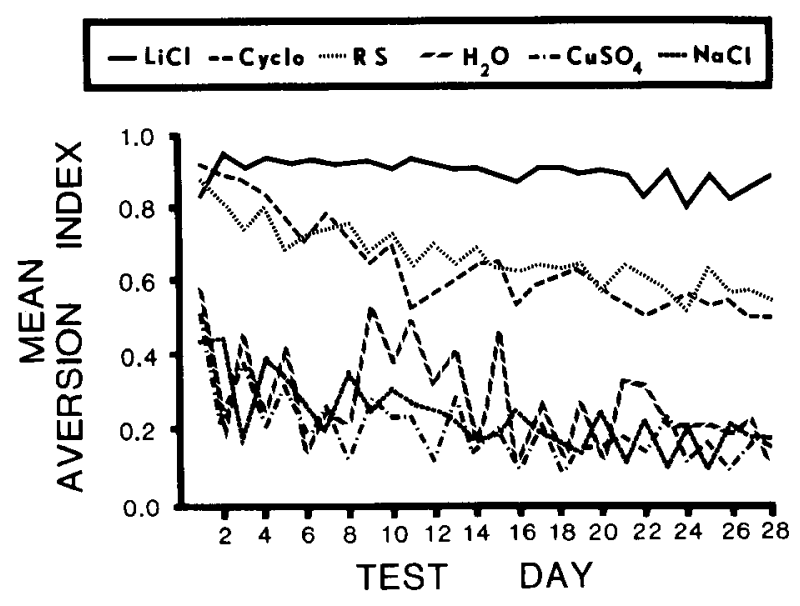

Figure 1. Mean saccharin aversion indices for six groups of rats dosed with LiCl (375 mg/kg), Cyclo (198 mg/kg), RS $(210 \mathrm{mg} / \mathrm{kg}), \mathrm{H}_{2} \mathrm{O}(.5-1.8 \mathrm{cc}), \mathrm{CuSO}_{4}(30 \mathrm{mg} / \mathrm{kg})$, or $\mathrm{NaCl}$ (375 mg/kg). 
$x$ day $[F(27,648)=1.76, p<.05]$. Figure 2 clarifies the triple interaction effect and shows the daily mean AIs for males vs. females for $\mathrm{LiCl}, \mathrm{Cyclo}$, and RS groups. LiCl-dosed rats of both sexes showed strong sustained aversion throughout the 28-day period. However, for Cyclo-dosed rats, both males and females showed extinction, with females extinguishing faster and more completely. Separation tests indicated no difference on Days 1-3, but males showed higher AI values, indicating higher resistance to extinction, on Days 4-28. RS-dosed males showed sustained aversions throughout the 28-day period (i.e., as strong as $\mathrm{LiCl}$ subgroups); however, the females showed rapid extinction after Day 1. Days 228 for RS all produced significantly different AIs for males vs. females. This strong sex difference in resistance to extinction for the Cyclo and RS groups also accounted for the sex $\times$ day and the drug $\times$ day interactions when compared with the sustained CTA shown by both sexes across 28 days for the $\mathrm{LiCl}$ group rats (Figures 1 and 2 ).

ANOVA for number of days that AIs exceeded .75 indicated significant effects for drug $\times \operatorname{sex}[F(5,24)=$ $3.21, \mathrm{p}<.05]$, drug $[\mathrm{F}(5,24)=19.01, \mathrm{p}<.05]$, and $\operatorname{sex}[F(1,24)=6.81, p<.05]$. RS males showed no extinction (mean $=28.0$ days), whereas the females rapidly extinguished their CTA responses (mean = 5.33 days). However, $\mathrm{LiCl}$ males (mean $=26.7$ days) were not significantly different from females (mean $=27.7$ days), which accounted for the two-way interaction term. Comparisons for the drug main effect indicated that $\mathrm{LiCl}$ produced the longest CTA (mean $=27.2$ days; $p<.05$ ), compared with $\mathrm{RS}$ (mean $=$ 16.8 days) and Cyclo (mean $=16.1$ days). All three drugs produced significantly greater CTA than $\mathrm{CuSO}_{4}, \mathrm{NaCl}$, and $\mathrm{H}_{2} \mathrm{O}$. With regard to the sex effect, males (mean $=13.3$ days) showed more resistance to extinction than did females (mean $=7.88$ days).

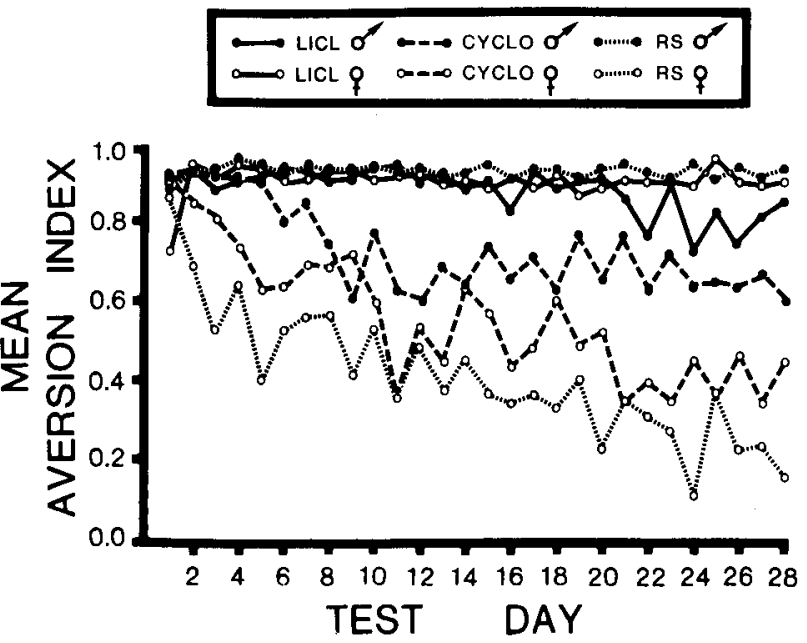

Figure 2. Mean saccharin aversion indices for male vs. female Philippine rice rats dosed with $\mathrm{LICl}(375 \mathrm{mg} / \mathrm{kg})$, Cyclo (198 $\mathrm{mg} / \mathrm{kg})$, or RS (210 mg/kg).
Thus, according to both dependent measures, $\mathrm{LiCl}$ produced the strongest and most sustained CTA effect of the substances tested. The $375-\mathrm{mg} / \mathrm{kg}$ dose level of $\mathrm{LiCl}$ led to no apparent extinction of CTA responses in either sex over the 28 days. Although $\mathrm{CuSO}_{4}$ was reported by Nachman and Hartley (1975) to be an effective CTA drug for Sprague-Dawley rats, when given by ip injection, no significant CTA effect was produced by this drug under our test regimen with wild rice rats and gavage dosing. Cyclo and RS were confirmed to be effective conditioning agents, but males showed more resistance to extinction than females at the levels tested.

Both male and female subgroups for $\mathrm{LiCl}$, Cyclo, and RS exhibited high levels of CTA on Day 1 of extinction (Figure 2). The comparatively rapid extinction of female as compared with male $R$. $r$. mindanensis confirms the previously reported sex differences in extinction for $R$. norvegicus (Chambers \& Sengstake, 1976; Sengstake, Chambers, \& Thrower, 1978). The sex difference was most apparent with RS and to a lesser degree with Cyclo. Toxicity data for RS tested with Norway and Bandicota rats indicate females to be 1.5 to 5 times more sensitive than males (Brooks \& Htun, 1980). Thus, explanations based on relative toxicity would predict the opposite effect to that observed-at equivalent dosages, females should have been more severely affected by RS than males and have shown greater sustained CTA after the 2-day recovery period.

\section{EXPERIMENT 2}

When rats freely ingest drugs, toxicosis avoidance and escape from drug distress is controlled primarily by a feed-back mechánism involving taste cues and their association with internal drug effects (Rusiniak et al., 1976). Nachman and Ashe (1973) compared ip injection, stomach tube, and subcutaneous routes of $\mathrm{LiCl}$ administration $(3.0 \mathrm{meq} / \mathrm{kg})$ in albino rats and found essentially no differences in CTA in a 1-day test. Experiment 2 was undertaken to compare both the degree and duration of CTA over a 28-day period when three dose levels of $\mathrm{LiCl}$ were administered by free ingestion, gavage, or ip injection to Philippine rice rats.

\section{Method}

Subjects and Apparatus. Seventy-two Philippine rats ( 36 males and 36 females) were used as subjects. The rats weighed between 102 and $292 \mathrm{~g}$ and were judged to be 6 to 24 months old at the start of testing.

Rat-housing facilities, light-dark schedule, test cages, and fluid intake measurements were the same as those described for Experiment 1 .

Drugs. The rats were dosed with either $\mathrm{LiCl}$ (Lithium Corp. of America, Bessemer City) or deionized water (controls). Again, the drug was prepared as a wt/wt solution in deionized water.

Procedures. Rats were randomly assigned to one of three groups ( $n=24 /$ group; 12 male and 12 female), which were based on modes 
of drug administration (i.e., free ingestion, gavage, or ip injection). Within each group, rats were also assigned randomly to one of four dose conditions that received low, moderate, or high doses of $\mathrm{LiCl}$ or water (control); these assignments were balanced according to sex ( $n=6 /$ condition; 3 males and 3 females).

The procedure again consisted of four successive phases: the 14day deprivation-adjustment phase, the 1-day saccharin-drug phase, the 2-day drug-recovery phase, and the 28-day CTAassessment phase. During the 1-day saccharin-drug phase (Day 15), rats in the free-ingestion group were presented two bottles containing $\mathrm{LiCl}$ dissolved in the $.25 \%$ saccharin-flavored water. Concentrations of $\mathrm{LiCl}$ in solution (.5-5.0\%) were prepared based upon individual rat body weights and average 2 -h water consumptions during the 14-day deprivation-adjustment phase. These were intended to produce three nonoverlapping dose levels (low, moderate, and high). Rats in the gavage and injection groups were matched as closely as possible to those in the free-ingestion group based on body weight, sex, and average water consumption. For these later groups, treatment schedules were delayed by 1 and 2 days so that $\mathrm{LiCl}$ dosages and volumes could be calculated and prepared. Dosings were completed within $15 \mathrm{~min}$ after the 2-h saccharin exposure period.

Data and statistical analyses. Daily AI scores were calculated for each animal. The design was a 3 (mode) $\times 4$ (dosage) $\times 2$ (sex) $\times 28$ (day) four-way complete factorial analysis of variance, with days treated as a repeated measures factor (Winer, 1971). To analyze differences in the durations of CTA, the number of days that AIs exceeded .75 were counted for each rat. These data were analyzed as a 3 (mode) $\times 4$ (dosage) $\times 2$ (sex) analysis of variance. Mean separation tests (Duncan, 1955) were used to assess significant treatment effects, and the .05 level of significance was used throughout.

\section{Results and Discussion}

Free-ingestion group rats consumed the following mean ( $\pm \mathrm{SD}$; range) $\mathrm{LiCl}$ dosages, respectively: $36.0 \mathrm{mg} / \mathrm{kg}( \pm 8.1 ; \mathrm{R}=27.3-51.3) ; 105.0 \mathrm{mg} / \mathrm{kg}$ ( $\pm 33.0 ; R=73.6-155.0) ;$ and $368.1 \mathrm{mg} / \mathrm{kg}( \pm 64.9$; $\mathrm{R}=290.7-450.8$ ).

Figure 3 shows the mean Als for gavage, ingestion, and injection groups across 28 days of extinction testing for 36-, 105-, and 368-mg/ $\mathrm{kg}$ dosages of $\mathrm{LiCl}$, plus the water controls. For all modes of administration, the $368-\mathrm{mg} / \mathrm{kg}$ dose produced the greatest initial and longest-lasting CTA $[F(3,48)=$ $29.45, \mathrm{p}<.05$ ]. In addition, there was an overall extinction trend across the 28 -day test $[F(27,1296)=$ $19.52, \mathrm{p}<.05]$. However, the ingestion and injection groups showed AI values near .80 for the entire test. Comparisons for the day main effect indicated that AIs for Days 1, 2-3, 4-11, and 12-28 were ordered from highest to lowest.

Analyses of interaction terms indicated significant effects for mode $\times \operatorname{sex} \times$ day $[F(54,1296)=1.37$, $\mathrm{p}<.05]$, mode $x$ day $[\mathrm{F}(54,1296)=1.82, \mathrm{p}<.05]$, and dosage $\times$ day $[F(81,1296)=1.42, \mathrm{p}<.05]$. Comparisons of all means constituting the triple interaction yielded a complex pattern, and only general trends were indicated. For the gavage group, there were no sex differences shown, a result in agreement with Experiment 1. For the ingestion group, females showed slightly higher AIs than did males for the middle portion of the test (Days 3-21). For the injection group, males showed higher AIs than females

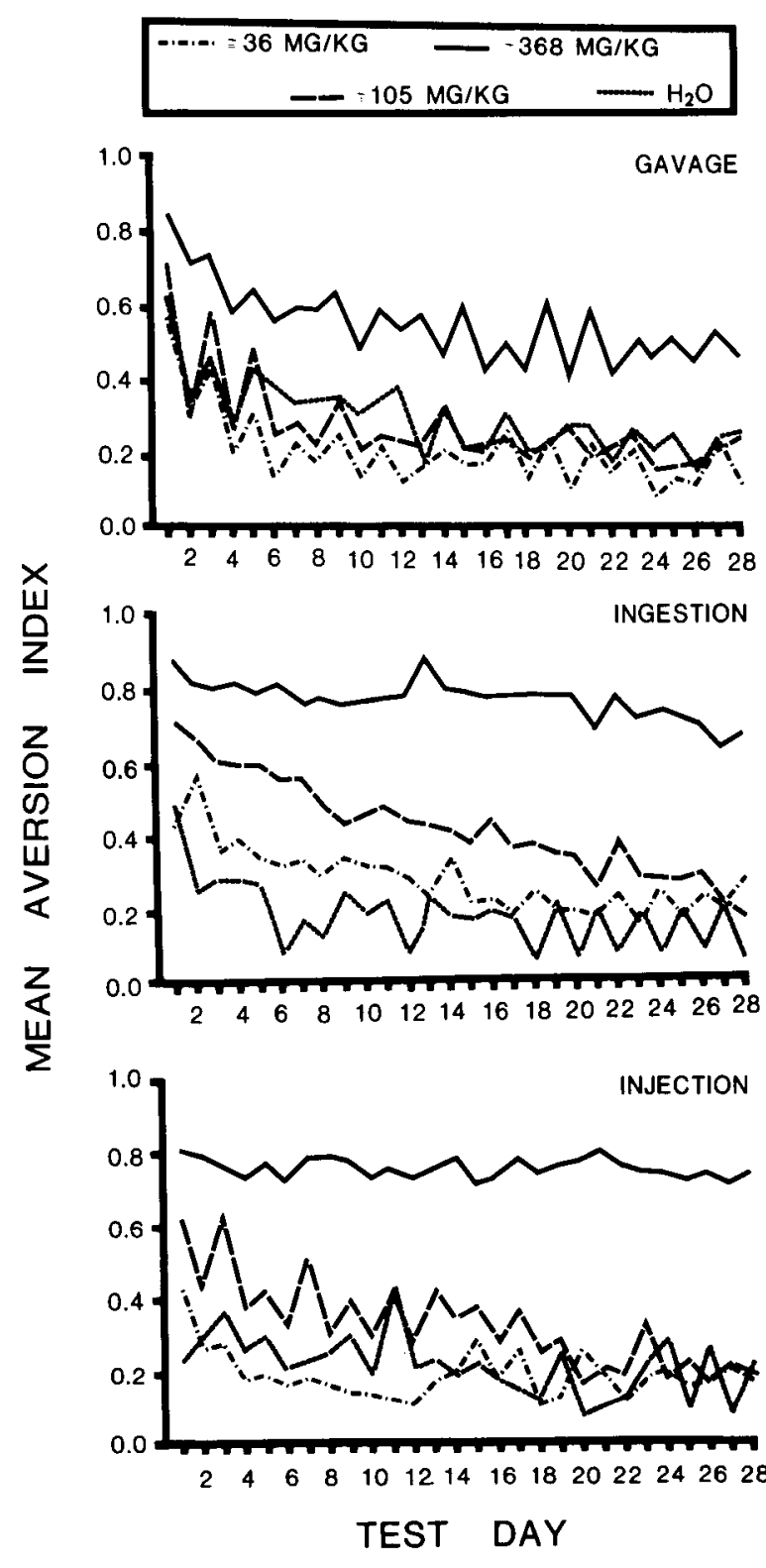

Figure 3. Mean saccharin aversion Indices for three modes of LICl administration (gavage, ingestion, ip injection) with separate groups of rats recelving $\mathrm{LICl}$ at 36,105 , or $368 \mathrm{mg} / \mathrm{kg}$ vs. $\mathrm{H}_{2} \mathrm{O}$ (.5-1.8 cc).

through Day 17, but there were no differences beyond Day 18.

As indicated in Figure 3, the mode $x$ day interaction effect stemmed from rapid extinction of the gavage group relative to the other modes. These animals had the highest AIs on Days 1-3 but the lowest on Days 24-28. Injection group rats showed the slowest extinction. The dosage $x$ day interaction effect stemmed from the $105-\mathrm{mg} / \mathrm{kg}$ rats' showing more rapid extinction than the $368-\mathrm{mg} / \mathrm{kg}$ dosed rats; the $36-\mathrm{mg} / \mathrm{kg}$ group and water-dosed controls showed no significant CTA.

A second ANOVA for number of days that each rat exceeded an $\mathrm{AI}$ of .75 yielded a significant dosage 
$x$ sex interaciion $[F(3,48)=3.18, p<.05]$ and $a$ dosage effect $[F(3,48)=32.59, p<.05]$. Duncan tests showed that males had more $\mathrm{AI}>.75$ days (mean $=$ 23.7) than females (mean $=14.3$ ) at the $368-\mathrm{mg} / \mathrm{kg}$ dosage. However, at the $105-\mathrm{mg} / \mathrm{kg}$ dosage, the reverse was found-males (mean $=3.1$ ) vs. females (mean $=6.0$ ). For the dosage term, $368 \mathrm{mg} / \mathrm{kg}$ produced a mean of 19.0 days of CTA which was significantly different from $105 \mathrm{mg} / \mathrm{kg}$ (mean $=4.5$ days) and $36 \mathrm{mg} / \mathrm{kg}$ (mean $=.5$ days).

The free-ingestion group showed as much, or more, aversion as rats dosed with $\mathrm{LiCl}$ by injection or gavage. This effect was greatest at the $368-\mathrm{mg} / \mathrm{kg}$ dosage, but was also evident to a relatively lesser degree at the $105-\mathrm{mg} / \mathrm{kg}$ dose. The $105-\mathrm{mg} / \mathrm{kg}$ dose range did not produce an extreme level of CTA for the injection group, even though a dosage slightly above this range $(125 \mathrm{mg} / \mathrm{kg})$ is a standard level used in most studies with albino rats (Riley \& Clarke, 1977). The sustained 2 -h saccharin-flavored water exposure period before injection could have been a factor producing this result; many studies have employed shorter (10-20 min) exposures before injection (cf. Bond \& Di Giusto, 1975; Deutsch, 1978).

The analysis for number of days that $\mathrm{AI} \geqslant .75$ indicated that females tended to extinguish aversions more rapidly than males at the $368-\mathrm{mg} / \mathrm{kg}$ dose level. However, at the $105-\mathrm{mg} / \mathrm{kg}$ dose level, the reverse was found. The existence of such subtle interactions should be considered in the development of potential applications of CTA to vertebrate damage control. However, the high degree of sustained aversion for the $368-\mathrm{mg} / \mathrm{kg}$ free-ingestion group indicated that wild Philippine rats are capable of sustained onetrial learned aversion. This is an important observation concerning potential applications of CTA to reducing crop damage or grain-storage losses by this species.

\section{GENERAL DISCUSSION}

In the present study, lithium chloride was found to be the most effective agent in producing long-term CTA in wild Philippine rice rats. Cyclo and RS were found to be significantly less effective than $\mathrm{LiCl}$ in Experiment 1, but these agents produced as much aversion as $\mathrm{LiCl}$ for the first 1-2 days of extinction. Our results tend to support those of Elkins (1973) indicating that there are wide variations in extinction rates among animals. Additionally, a short 1-2-day preference test provides very limited usefulness for comparing the degree or predicting the resistance-toextinction of CTA. Generally, both of our dependent measures (AI for each rat or number of days on which $\mathrm{AI}>.75$ ) led to similar statistical inferences.

Experiment 2 indicated that mode of $\mathrm{LiCl}$ dosing interacted with both the sex $x$ day and day factors. Generally, the free-ingestion group showed the greatest resistance to extinction, but the effect was only on the order of .1 AI units above the gavage and ip injection groups. For the mode $x$ sex $x$ day interaction, the magnitude of differences between means was also of this order. Our finding that mode as a main effect was nonsignificant is in agreement with Nachman and Ashe (1973), who found no CTA difference when the ip, subcutaneous, and stomachintubation modes were used for dosing $\mathrm{LiCl}$ into male Sprague-Dawley rats. Other modes and other drugs do apparently lead to differences in CTA, however. Coussens (1974) found, for example, that rats showed greater CTA when dosed ip vs. iv with $\alpha$ amphetamine.

Throughout Experiment 2, procedures were used to ensure that all rats, regardless of mode, received the same dosages (i.e., rats were matched by sex and individual body weights). However, certain dosing factors could not be controlled. Amounts of saccharin solution drunk, times between drinking and $\mathrm{LiCl}$ dosing, precapture experience with rodenticides, and ages of the animals were only partially controlled. It is likely that the free-injection rats drank less saccharinflavored water, had less opportunity for learned safety (Bond \& Di Giusto, 1975; Deutsch, 1978; Kalat, 1977), and experienced immediate $\mathrm{LiCl}$ effects in closer temporal contiguity to saccharin taste than the gavage or ip injected groups. Nevertheless, despite these limitations, equal initial levels of CTA were produced for all three modes at the $368-\mathrm{mg} / \mathrm{kg}$ dose level. Differences in CTA for the three different modes of dosing appeared several days into the extinction test.

Another aspect of our procedure for dosing of the free-ingestion group should be noted. This group received a combination of saccharin $(.25 \%)$ and $\mathrm{LiCl}$ $(.5-5.0 \%)$ flavors on the drug treatment day. During the 28-day CTA-assessment phase, however, only $.25 \%$ saccharin was available as the conditioned taste stimulus. Again, despite the complex flavor change, CTA was maintained for 28 days in the $368-\mathrm{mg} / \mathrm{kg}$ group. This result confirmed that: (1) saccharin was a highly salient taste for use in CTA studies and (2) transfer of CTA from $\mathrm{LiCl}$ bait to an agricultural resource could prove feasible with saccharin as the flavor mediator.

Although choice of drug and drug dosage are prime considerations in the selection of aversive agents for CTA vertebrate-damage-control applications, several other factors are equally important. We have shown that drugs, mode of dosing, and sex can interact to effect CTA extinction rates in wild Philippine rats.

\section{REFERENCES}

Bond, N., \& Di Giusto, E. Amount of solution drunk is a factor in the establishment of taste aversion. Animal Learning \& Behavior, 1975, 3, 81-84. 
Brooks, J. E., \& HTUN, P. T. Laboratory evaluation of scilliroside used as a rodenticide against the lesser bandicoot rat, Bandicota bengalensis. Journal of Hygiene, 1980, 85, 227-234.

Chambers, K. C., \& Sengstake, C. B. Sexually dimorphic extinction of a conditioned taste aversion in rats. Animal Learning \& Behavior, 1976, 4, 181-185.

Coussens, W. Conditioned taste aversion: Route of drug administration. In J. M. Singh \& H. Lal (Eds.), Second International Symposium on Drug Addiction. New York: Stratton, 1974.

DeUTsch, R. Effects of CS amount on conditioned taste aversion at different CS-US intervals. Animal Learning \& Behavior, $1978,6,258-260$.

Duncan, D. B. Multiple range and multiple F tests. Biometrics, 1955, 11, 1-42.

Elxins, R. L. Individual differences in bait shyness: Effects of drug dose and measurement technique. Psychological Record, $1973,23,349-458$.

Garcia, J., Kimeldonf, D. J., \& Koelifing, R. A. Conditioned aversion to saccharin resulting from exposure to gamma radiation. Science, 1955, 122, 157-158.

Garcia, J., Hankins, W. G., \& Rusiniak, K. W. Behavioral regulation of the milieu interne in man and rat. Science, 1974, $185,824-831$.

KALAT, J. W. Studies of "learned-safety" or "learned noncorrelation" as a mechanism in taste, aversion learning. In L. M. Barker, M. R. Best, \& M. Domjan (Eds.), Learning mechanisms in food selection. Waco, Tex: Baylor University Press, 1977.
Nachman, M., \& Ashe, J. H. Learned taste aversions in rats as a function of dosage, concentration, and route of administration of LiCl. Physiology \& Behavior, 1973, 10, 73-78.

Nachman, M., \& Hartuey, P. L. Role of illness in producing learned aversions in rats: A comparison of several rodenticides. Journal of Comparative and Physiological Psychology, 1975, 89, 1010-1018.

Riley, A. L., \& Clarke, C. M. Conditioned taste aversions: A bibliography. In L. M. Barker, M. R. Best, \& M. Domjan (Eds.), Learning mechanisms in food selection. Waco, Tex: Baylor University Press, 1977.

Rusiniak, K. W., Garcia, J., \& Hankins, W. G. Bait shyness: Avoidance of the taste without escape from the illness in rats. Journal of Comparative and Physiological Psychology, 1976, 90, 460-467.

Sengstake, C. B., Chambers, K. C., \& Thrower, J. H. Interactive effects of fluid deprivation and testosterone on the expression of a sexually dimorphic conditioned taste aversion. Journal of Comparative and Physiological Psychology, 1978, 92, 1150-1155.

WINER, B, J. Statistical principles in experimental design. New York: McGraw-Hill, 1971.

(Manuscript received December 22, 1981; revision accepted June 28,1982 .) 